\title{
COEXISTENCE OF CUTANEOUS MUCORMYCOSIS AND SCROFULODERMA IN AN IMMUNODEFICIENT CHILD
}

\author{
Mahalakshmi V1, Gayathri Rajesh², Maharaja $K^{3}$, Adikrishnan $S^{4}$, Sudha $R^{5}$
}

${ }_{1}$ Professor, Department of Dermatology, Sri Ramachandra University and Research Institute.

${ }^{2}$ Senior Resident, Department of Dermatology, Sri Ramachandra University and Research Institute.

${ }^{3}$ Assistant Professor, Department of Dermatology, Sri Ramachandra University and Research Institute.

${ }^{4}$ Associate Professor, Department of Dermatology, Sri Ramachandra University and Research Institute.

5 Professor, Department of Dermatology, Sri Ramachandra University and Research Institute.

\begin{abstract}
Severe Combined Immunodeficiency (SCID) is a genetic disorder characterised by the disturbed development of functional T cells and B cells caused by numerous genetic mutations.(1) These patients are extremely vulnerable to infectious diseases and early death.(1) A 1-year-old child, known case of SCID since 8 months of age, presented with septic shock. He had a swelling on the left hand for 1 month and over left hand, which was a prior site of IV cannulation and swelling over axilla since 6 months. The child received multiple blood transfusions, though no bone marrow transplant was done. We entertained a differential diagnosis of cutaneous tuberculosis, atypical mycobacterial infection, deep fungal infection and foreign body granuloma for the left hand nodule. We thought of scrofuloderma with lymphadenopathy as a diagnosis for the axillary lesion. Biopsy of the hand lesion-multiple broad aseptate hyphae with granulomatous infiltrates suggesting mucormycosis. FNAC of axillary lymph node-necrotising lymphadenitis with AFB positive. Chest X-ray HRCT-PCP Pneumonia. He was started on IV Amphotericin-B.
\end{abstract}

\section{KEYWORDS}

SCID Septic Shock, Hand swelling, Axilla swelling, Trauma site.

HOW TO CITE THIS ARTICLE: Mahalakshmi V, Rajesh G, Maharaja K, et al. Coexistence of cutaneous mucormycosis and scrofuloderma in an immunodeficient Child. J. Evolution Med. Dent. Sci. 2016;5(8):371-372, DOI: 10.14260/jemds/2016/84

\section{INTRODUCTION}

\section{CASE REPORT}

A 1-year-old child known case of SCID (Diagnosed outside by peripheral blood cytometry) since 8 months of age presented to our hospital with septic shock. He was treated earlier with Inj. vancomycin and fluconazole. On admission he was continued on IV antibiotics. He was referred to the Dermatology Department for a swelling on the left hand and left axilla.

The child's mother gave history of swelling, appearing 1 month ago over left hand which was a prior site of IV cannulation and swelling over axilla since 6 months. The child had received multiple blood transfusions, though no bone marrow transplant was done. On examination- A single hyperpigmented nodule $3 \times 2 \mathrm{~cm}$ was present over dorsum of left hand. Another nodule of size $5 \times 2 \mathrm{~cm}$ was present over his left anterior axillary fold with axillary lymphadenopathy. We entertained a differential diagnosis of cutaneous tuberculosis, atypical mycobacteria infection, deep fungal infection and foreign body granuloma for the left hand nodule. We thought of scrofuloderma with lymphadenopathy as a diagnosis for the axillary lesion.

\section{INVESTIGATIONS}

There was pancytopenia. Biopsy of the hand lesionmultiple broad aseptate hyphae with granulomatous

Financial or Other, Competing Interest: None.

Submission 18-11-2015, Peer Review 24-11-2015,

Acceptance 26-11-2015, Published 28-01-2016.

Corresponding Author:

Dr. Gayathri Rajesh

PLT No: 212, $42^{\text {nd }}$ Street, $8^{\text {th }}$ Sector.

KK Nagar, Chennai.

E-mail: groorygaya@hotmail.com

DOI: $10.14260 /$ jemds/2015/84
Infiltrates suggesting mucormycosis. FNAC of axillary lymph node showed necrotising lymphadenitis with AFB positive. Chest x-ray HRCT-PCP pneumonia. He was started on in Amphotericin-B.

He subsequently developed a maculopapular rash secondary to a drug reaction/viral exanthema/infection associated hemophagocytosis/GVHD, which led on to liver cell failure and hence despite the aggressive treatment the child succumbed and died.

\section{CONCLUSION}

Prevalence of SCID-1 in 100000 births. Common cutaneous manifestations and typical infections can provide clinical clues in diagnosing SCID. Hence, this case is presented to highlight the need to recognise such infections at the earliest so that early intervention and bone marrow transplantation is successful in these patients.

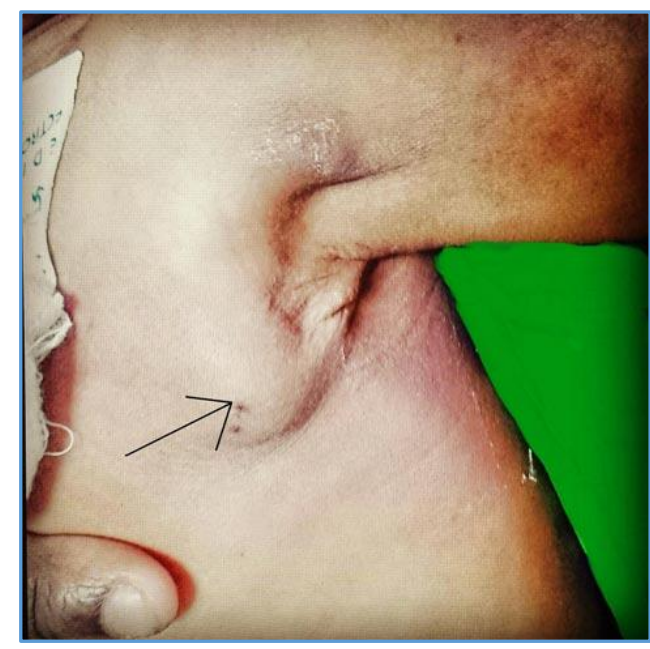

Fig. 1: Axillary Lymphnode 


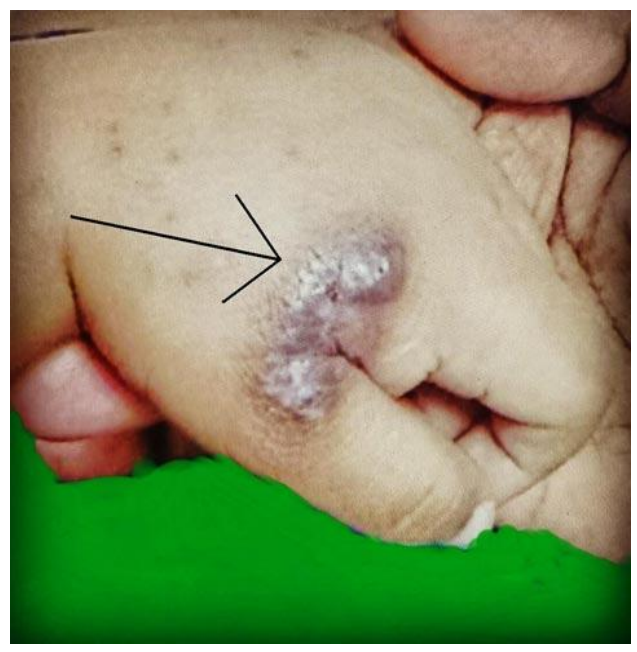

\section{REFERENCES}

1. Stephan J, Vlekova M, Le Deist F, et al. Severe combined immunodeficiency: a retrospective single-center study of clinical presentation and outcome in 117 cases. J Pediatr. 1993;123:921-928.

Fig. 2: Nodule in the Dorsum of hand 